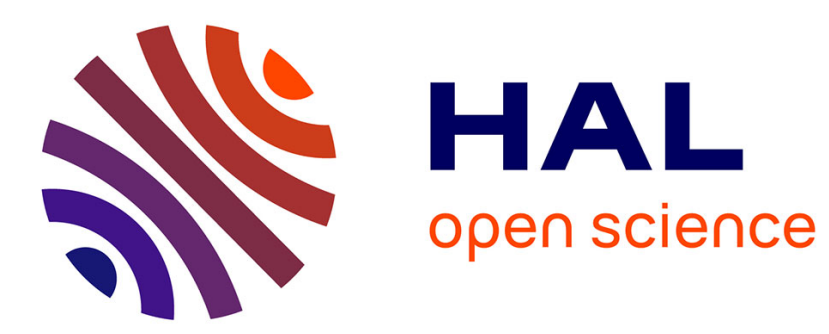

\title{
Adaptive Nonlinear Control of Wind Energy Conversion System with PMS Generator
}

Abdelmounime El Magri, Fouad Giri, Abderrahim Elfadili, Luc Dugard

\section{To cite this version:}

Abdelmounime El Magri, Fouad Giri, Abderrahim Elfadili, Luc Dugard. Adaptive Nonlinear Control of Wind Energy Conversion System with PMS Generator. ALCOSP 2013 - 11th IFAC International Workshop on Adaptation and Learning in Control and Signal Processing, Jul 2013, Caen, France. pp.n/c. hal-00818417

\section{HAL Id: hal-00818417 https://hal.science/hal-00818417}

Submitted on 26 Apr 2013

HAL is a multi-disciplinary open access archive for the deposit and dissemination of scientific research documents, whether they are published or not. The documents may come from teaching and research institutions in France or abroad, or from public or private research centers.
L'archive ouverte pluridisciplinaire HAL, est destinée au dépôt et à la diffusion de documents scientifiques de niveau recherche, publiés ou non, émanant des établissements d'enseignement et de recherche français ou étrangers, des laboratoires publics ou privés. 


\title{
Adaptive Nonlinear Control of Wind Energy Conversion System with PMS Generator
}

\author{
A. El Magri*. F. Giri*, A. El Fadili*, L. Dugard** \\ * GREYC Lab, University of Caen, Caen, France (e-mail: magri_mounaim@ yahoo.fr). \\ ** Gipsa-Lab, UMR CNRS, ENSE3, BP 46, 38402 Saint Martin d'Hères cedex, France
}

\begin{abstract}
This paper addresses the problem of controlling wind energy conversion systems (WECS) which involve permanent magnet synchronous generator (PMSG) fed by IGBT-based buck-to-buck rectifier-inverter. The goal of the control is to maximize wind energy extraction and this necessitates letting the wind turbine rotor operate in variable-speed mode. The control strategy involves: (i) a nonlinear regulator designed by the backstepping technique; (ii) a sensorless online reference-speed optimizer designed to achieve the maximum power point tracking (MPPT) requirement. Considering the whole association 'converter-motor' makes it possible to consider, in addition to motor speed regulation, three other important control objectives such as power factor correction (PFC) with respect to the supply net and DC Link voltage regulation. To achieve these objectives, an adaptive control strategy is developed, based on a nonlinear model of the whole 'converter-motor' association. Adaptation is motivated by the uncertain nature of some motor characteristics, especially the mechanical parameters. It is formally shown that the proposed controller actually meets its control objectives. This theoretical result is confirmed by several simulations.
\end{abstract}

\section{INTRODUCTION}

Due to its renewable nature and reduced environmental impact, wind energy is already playing an important role in electricity generation worldwide and this role is expected to considerably grow up in the near future. Achieving maximum wind energy extraction in presence of varying wind speed conditions necessitates a varying turbine speed operation mode. Specifically, the turbine rotor velocity must be controlled so that its power-speed working point is constantly maintained near the optimal position (Fig. 2). This control objective is commonly referred to as 'maximum power point tracking (MPPT)' and its achievement guarantees optimal aerodynamic efficiency.

This paper focuses on the wind energy conversion system Fig 1. This includes a permanent magnet synchronous generator (PMSG) that converts wind turbine power to output voltage whose amplitude and frequency vary with wind speed. PMSG generators offer several benefits in wind power applications, due to their high power density, high efficiency (as the copper losses in the rotor disappear), and absence of gearbox and reduced active weight. These features make it possible to achieve with PMSG's high varying speed control performance and highly reliable operation conditions (reduced need for maintenance).

In the light of the above discussion, the global system including the wind turbine, the PMSG and the AC/DC/AC power converter has to be controlled to achieve accurate reference-speed tracking. The rotor speed reference $\left(\omega_{\text {ref }}\right)$ must be updated online, taking into account the current wind velocity $\left(v_{\text {win }}\right)$, so that the MPPT requirement is realized.

Existing MPPT methods can be divided in two classes. The first one includes those methods using explicitly the turbine power characteristic, e.g. (Senjyu et al., 2009). The second class includes methods based on extremum-seeking techniques that do not necessitate the knowledge of turbine characteristics, e.g. (Hong et al., 2009, Eftichios and Kostas, 2006, Kesraoui et al. 2011). In fact, the required wind speed measurement is a sort of average value of wind speed along the turbine blade. Besides, this is not easy to measure; the use of wind sensors entails additional cost and inevitably reduces reliability.

The obtained online speed-reference optimizer represents a key feature of our control strategy which, besides, involves turbine rotor speed regulation, DC link voltage regulation and adaptive state observation. Speed regulation is performed using a nonlinear regulator which, in addition, regulates the d-component of the stator current to zero, optimizing thus the delivered stator current. The voltage at the DC link between the $\mathrm{AC} / \mathrm{DC}$ rectifier and inverter is regulated to a constant reference value. In fact, the DC link voltage reference value should equal the nominal value of the PMS Generator. This regulation loop controls the reactive power control delivered to the grid. All previous regulation loops have been designed using the backstepping technique (Krstic et al., 1995). The nonlinear multi-loop (speed, current, voltage) controller thus obtained is formally shown, using Lyapunov stability, to meet its control objectives.

Several simulations show that the global state-feedback controller obtained performs well in presence of varying wind velocity and load torque.

The paper is organized as follows: the system under study (i.e. the PMSG aero generator and AC/DC/AC converter association) is modeled and given a state space representation in Section 2; the speed reference optimizer and multi-loop controller are designed and analyzed in Section 3; the simulations are presented in Section 4. 


\section{MODELING THE ASSOCIATION SYNCHRONOUS GENERATOR-AC/DC/AC CONVERTER}

\subsection{Modelling of the combination 'PMSG-PMW DC/AC converter'}

The controlled system, illustrated by Fig.1, includes a combination 'synchronous Generator-rectifier', on one hand, and a tri-phase DC/AC inverter, on the other hand. The rectifier is an $\mathrm{AC} / \mathrm{DC}$ converter operating, like the DC/AC rectifier, according to the known Pulse Wide Modulation (PWM) principle.

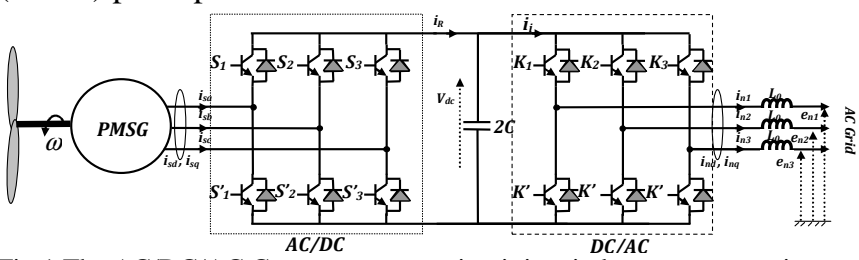

Fig. 1 The AC/DC/AC Converter power circuit in wind energy conversion system

Such a modelling is generally performed in the d-q rotating reference frame because the resulting components $i_{s d}$ and $i_{s q}$ turn out to be DC currents. It is shown in many places (e.g Wallmark, 2004) that the synchronous machine model, expressed in the $\mathrm{d}-\mathrm{q}$ coordinates, can be given the following state space form:

$\frac{d \omega}{d t}=-\frac{F}{J} \omega-\frac{K_{M}}{J} i_{s q}+\frac{1}{J} T_{g}$

$\frac{d i_{s q}}{d t}=-\frac{R_{s}}{L_{s}} i_{s q}-p i_{s d} \omega-\frac{K_{M}}{L_{s}} \omega-\frac{1}{L_{s}} v_{s q}$

$\frac{d i_{s d}}{d t}=-\frac{R_{s}}{L_{s}} i_{s d}+p i_{s q} \omega-\frac{1}{L_{s}} v_{s d}$

where $R_{s}$ and $L_{s}$ are the stator resistor and inductance, $J, F, p$ are the rotor inertia, viscous coefficient and number of poles pairs. $\omega$ is the rotor speed, $T_{g}$ is the load torque of the generator, $K_{M}$ is a flux generator constant and $v_{s d}, v_{s q}$ (and $i_{s d}, i_{s q}$ ) denote the averaged stator voltage (and current respectively) in the d-q coordinates (Park's transformation of the triphase stator voltages). The inverter is featured by the fact that the $\mathrm{d}$ - and q- stator voltages can be controlled independently. To this end, these voltages are expressed in function of the corresponding control action (see e.g. Michael et al., 1998):

$v_{s q}=v_{d c} u_{1} ; v_{s d}=v_{d c} u_{2} ; \bar{i}_{R}=u_{1} i_{s q}+u_{2} i_{s d}$

where $u_{1}=\bar{u}_{s q}, u_{2}=\bar{u}_{s d}$ represent the average d-and q-axis (Park's transformation) of the triphase duty ratio system $\left(s_{1}, s_{2}, s_{3}\right)$

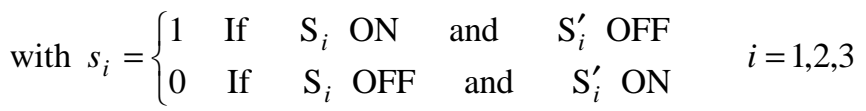

Now, let us introduce the state variables $x_{1}=\bar{\omega}, x_{2}=i_{s q}$, $x_{3}=i_{s d}$ where $(\bar{z})$ denote the average value on the modulation (PMW) period of $(z)$. Then, substituting (2) in (1a-b) yields the following state space representation of the association 'Generator-rectifier':

$$
\begin{aligned}
\frac{d x_{1}}{d t} & =-\frac{F}{J} x_{1}-\frac{K_{M}}{J} x_{2}+\frac{T_{g}}{J} \\
\frac{d x_{2}}{d t} & =-\frac{R_{s}}{L_{s}} x_{2}-p x_{1} x_{3}+\frac{K_{M}}{L_{s}} x_{1}-\frac{1}{L_{s}} u_{1} v_{d c} \\
\frac{d x_{3}}{d t} & =-\frac{R_{s}}{L_{s}} x_{3}+p x_{1} x_{2}-\frac{1}{L_{s}} u_{2} v_{d c}
\end{aligned}
$$

\subsection{DC/AC inverter modelling}

The inverter circuit (DC/AC) is presented in Fig.1. The power supply net is connected to a converter which consists of a three phase converter having 6 semiconductors (IGBTs with anti-parallel diodes for bidirectional current flow mode) displayed in three legs 1, 2 and 3. The 6 semiconductors are considered as ideal switches. Only one switch on the same leg can be conducting at the same time.

Applying Kirchhoff's laws, this subsystem is described by the following set of differential equations:

$L_{0} \frac{d}{d t}\left[i_{n 123}\right]=v_{d c}\left[k_{123}\right]-\left[e_{n 123}\right]$

$2 C \frac{d v_{d c}}{d t}=i_{r}-i_{i}$

$i_{i}=\left[k_{123}\right]^{T}\left[i_{n 123}\right]$

where $\left[i_{n 123}\right]=\left[\begin{array}{lll}i_{n 1} & i_{n 2} & i_{n 3}\end{array}\right]^{T}$ are the input currents in the electric grid, $\left[e_{n 123}\right]=\left[\begin{array}{lll}e_{n 1} & e_{n 2} & e_{n 3}\end{array}\right]^{T}$ are the sinusoidal triphase net voltages (with known constant frequency $\omega_{n}$ ), $v_{d c}$ denotes the voltage in capacitor $2 \mathrm{C}, i_{i}$ designates the input current inverter, and $k_{i}$ is the switch position function taking values in the discrete set $\{0,1\}$. Specifically:

$k_{i}=\left\{\begin{array}{c}1 \text { if } \quad K_{i} \text { is } O N \text { and } K_{i}^{\prime} \text { is } O F F \\ 0 \text { if } \quad K_{i} \text { is } O F F \text { and } K_{i}^{\prime} \text { is } O N\end{array} \quad(i=1,2,3)\right.$

To simplify the triphase representation (4a) for the synthesis of control laws, the Park transformation is invoked again.

$$
\begin{aligned}
& \frac{d i_{n d}}{d t}=-\frac{1}{L_{0}} E_{n d}+\omega_{n} i_{n q}+\frac{1}{L_{0}} u_{n d} v_{d c} \\
& \frac{d i_{n q}}{d t}=-\frac{1}{L_{0}} E_{n q}-\omega_{n} i_{n q}+\frac{1}{L_{0}} u_{n q} v_{d c} \\
& 2 C \frac{d v_{d c}}{d t}=i_{R}-i_{i}
\end{aligned}
$$

where $\left(E_{n d}, E_{n q}\right),\left(i_{n d}, i_{n q}\right)$ and $\left(u_{n d}, u_{n q}\right)$ denote the averaged network voltage, current and input control of the inverter in d-q coordinate (Park's transformation).

The power absorbed by the DC/AC converter is given by the well known expression $P_{\text {Load }}=i_{i} v_{d c}$. On the other hand, the power released by the network is given by $P_{\text {OUT }}=\left[e_{n 123}\right]^{T}\left[i_{n 123}\right]=E_{n d} i_{n d}+E_{n q} i_{n q}$. Using the power 
conservation principle, one has $P_{\text {Load }}=P_{\text {OUT }}$ or, equivalently $i_{i} v_{d c}=E_{n d} i_{n d}+E_{n q} i_{n q}$. Also, from (6a-b) one immediately gets that:

$2 v_{d c} \frac{d v_{d c}}{d t}=-\frac{1}{C} E_{n d} i_{n d}-\frac{1}{C}\left(E_{n q} i_{n q}-v_{d c} \bar{i}_{R}\right)$

$\frac{d i_{n d}}{d t}=-\frac{1}{L_{0}} E_{n d}+\omega_{n} i_{n q}+\frac{1}{L_{0}} u_{n d} v_{d c}$

$\frac{d i_{n q}}{d t}=-\frac{1}{L_{0}} E_{n q}-\omega_{n} i_{n d}+\frac{1}{L_{0}} u_{n q} v_{d c}$

Let us introduce the state variables $x_{4}=\bar{v}_{d c}^{2}, \quad x_{5}=\bar{i}_{n d}$, $x_{6}=\bar{i}_{n q}$ and $u_{3}=\bar{u}_{n d}, u_{4}=\bar{u}_{n q}$ represent the average d-and q-axis components of the three-phase duty ratio system $\left(k_{1}, k_{2}, k_{3}\right)$.

The state space equations obtained, up to now, are put together to get a state-space model of the whole system including the AC/DC/AC converters combined with the synchronous generator. For convenience, the whole model is rewritten here for future reference:

$\frac{d x_{1}}{d t}=-\frac{F}{J} x_{1}-\frac{K_{M}}{J} x_{2}+\frac{T_{g}}{J}$

$\frac{d x_{2}}{d t}=-\frac{R_{s}}{L_{s}} x_{2}-p x_{1} x_{3}+\frac{K_{M}}{L_{s}} x_{1}-\frac{1}{L_{s}} u_{1} v_{d c}$

$\frac{d x_{3}}{d t}=-\frac{R_{s}}{L_{s}} x_{3}+p x_{1} x_{2}-\frac{1}{L_{s}} u_{2} v_{d c}$

$\frac{d x_{4}}{d t}=-\frac{1}{C} E_{n d} x_{5}-\frac{1}{C}\left(E_{n q} x_{6}-v_{d c} \bar{i}_{R}\right)$

$\frac{d x_{5}}{d t}=-\frac{1}{L_{0}} E_{n d}+\omega_{n} x_{6}+\frac{1}{L_{0}} u_{3} v_{c d}$

$\frac{d x_{6}}{d t}=-\frac{1}{L_{0}} E_{n q}-\omega_{n} x_{5}+\frac{1}{L_{0}} u_{4} v_{c d}$

\section{CONTROL OBJECTIVES}

There are four operational control objectives:

CO1. Optimization of wind energy extraction: one must determine the optimal reference speed that maximizes the extracted energy.

CO2. Speed regulation: the machine speed $\omega$ must track, as closely as possible, a given reference signal $\omega_{\text {ref }}$. This reference has been obtained from the MPPT strategy (e.g. (Senjyu et al., 2009)).

CO3. The inverter output currents $\left(i_{n 1}, i_{n 2}, i_{n 3}\right)$ must be sinusoidal with the same frequency as the supplied power grid, the reactive power in the AC grid must be well regulated.

CO4. Controlling the continuous voltage $v_{d c}$ so that it tracks a given reference signal $v_{d c r e f}$. This generally is set to a constant value equal to the nominal voltage entering the converter and machine.
CO5. Regulating the current $i_{s d}$ to a reference value $i_{d r e f}$, preferably equal to zero in order to optimize the stator current (see e.g. Muhammad and Rashid, 2001).

To achieve these objectives, a nonlinear state feedback controller will be designed in the next subsection.

\section{NONLENEAR ADAPIVE CONTROLLER DESIGN}

\subsection{Wind senseless rotor speed reference optimization}

The optimization strategy is to search a reference speed $\omega_{\text {opt }}$, in order to achieve optimal speed ratio working conditions of the wind turbine to capture the maximum energy from the wind. The wind power acting on the swept area of the blade A is a function of the air density $\rho\left(\mathrm{Kg} / \mathrm{m}^{3}\right)$ and the wind speed $v_{\text {win }}(m / s)$. The transmitted power $P(W)$ is generally deduced from the wind power using the power coefficient $C_{p}$, as:

$$
P=\frac{1}{2} C_{p} \rho \mathrm{A} v_{w i n}^{3}
$$

The power coefficient $C_{p}$ is a non-linear function of the tip speed-ratio $\lambda=R \omega / v_{\text {win }}$ (where $R$ is the turbine radius), which depends on the wind velocity and the rotation speed of the generator rotor $\omega(\mathrm{rad} / \mathrm{s})$. Fig.2 represents the transmitted power according to the rotor PMSG speed for various values of the wind speed.

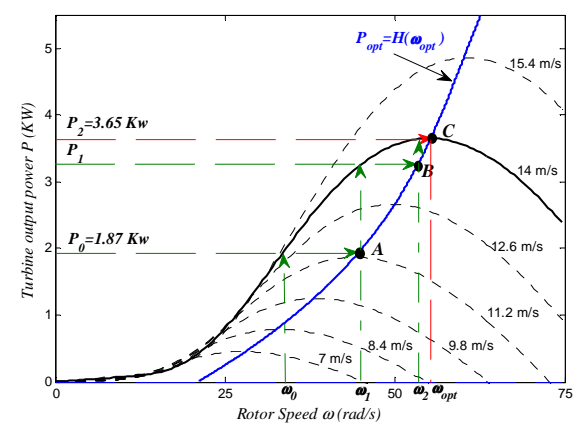

Fig.2 Turbine Power Characteristics (Pitch angle $=0^{\circ}$ )

The summits of these curves give the maximum 'extractable' power $P_{o p t}$ and so represent the optimal points. Each one of these points is characterized by the optimal speed $\omega_{\text {opt }}$. It is readily seen from Fig. 2 that for any wind velocity value, say $v_{w i n}^{i}$, there is a unique couple $\left(\omega_{i}, P_{i}\right)$ that involves the largest extractable power. The set of all such optimal couples $\left(\omega_{i}, P_{i}\right)$ is represented by the blue curve in Fig.2. A number of such couples have been collected from Fig.2 and interpolated to get a polynomial function $\omega_{\text {opt }}=F\left(P_{\text {opt }}\right)$. Let the obtained polynomial be denoted:

$F(P)=h_{n} P^{n}+h_{n-1} P^{n-1}+\ldots+h_{1} P+h_{0}$ 
The function $F($.$) defines the speed-reference optimizer. This$ function will suggest the optimal point $\left(P_{o p t}, \omega_{o p t}\right)$ (see El Magri et al., 2013).

\subsection{Speed regulator design for synchronous generator}

A control law for the remaining (actual) control input $u_{1}$ will now be determined, based on equations $(9 a-b)$, in order to guarantee speed reference tracking. Following the backstepping technique (Krstic et al., 1995), let $z_{1}$ denote the speed tracking error:

$z_{1}=x_{1}-\omega_{r e f}=x_{1}-x_{1}^{*}$

In view of (9a), the above error undergoes the following equation:

$\dot{z}_{1}=-\frac{F}{J} x_{1}-\frac{K_{M}}{J} x_{2}+\frac{T_{g}}{J}-\dot{x}_{1}^{*}$

In (13), the quantity $\alpha=-K_{M} x_{2}$ stands up as a (virtual) control input for the $z_{1}$-dynamics because the actual control inputs (presently $u_{1}$ ) act on $z_{1}$ indirectly through $\alpha$. The Lyapunov function candidate is considered as:

$V_{1}=0.5 z_{1}^{2}$

Deriving $V_{1}$ along the trajectory of (13) yields:

$\dot{V}_{1}=z_{1} \dot{z}_{1}=z_{1}\left(-\frac{F}{J} x_{1}-\frac{K_{M}}{J} x_{2}+\frac{T_{g}}{J}-\dot{x}_{1}^{*}\right)$

This suggests for the (virtual control) $\alpha$ the following control law:

$\alpha^{*}=\left(-c_{1} J z_{1}+F x_{1}-T_{g}+J \dot{x}_{1}^{*}\right)$

with $c_{1}>0$ a design parameter. Indeed, substituting $\alpha^{*}$ to $\alpha$ gives $\dot{V}_{1}=-c_{1} z_{1}^{2}$ which clearly is negative definite in $z_{1}$. The point is that $J, F$ and $T_{g}$ are unknown. Then, these must be replaced in (14) by their estimates (denoted $\hat{J}, \hat{F}, \hat{T}_{g}$ which have yet to be determined). Doing so, one gets the following stabilizing function:

$\hat{\alpha}^{*}=\left(-c_{1} \hat{J} z_{1}+\hat{F} x_{1}-\hat{T}_{g}+\hat{J} \dot{x}_{1}^{*}\right)$

As $\alpha=-K_{M} x_{2}$ is just a virtual control input, one cannot set $\alpha=\hat{\alpha}^{*}$. Nevertheless, the above expression of $\hat{\alpha}^{*}$ is retained and a new error is introduced:

$z_{2}=\alpha-\hat{\alpha}^{*}$

Using (17)-(18), it follows from (13) that the $z_{1}$-dynamics undergoes the following equation:

$\dot{z}_{1}=-c_{1} z_{1}+\frac{1}{J}\left[z_{2}+\tilde{J}\left(c_{1} z_{1}-\dot{x}_{1}^{*}\right)+\tilde{T}_{g}-\tilde{F} x_{1}\right]$

where $\tilde{J}=J-\hat{J}, \tilde{F}=F-\hat{F}$ and $\tilde{T}_{g}=T_{g}-\hat{T}_{g}$

The next step consists in determining the control input $u_{1}$ so that the $\left(z_{1}, z_{2}\right)$ error system is asymptotically stable. First, let us built the trajectory of the error $z_{2}$. Deriving $z_{2}$ with respect to time and using (18) gives:

$\dot{z}_{2}=-K_{M} \dot{x}_{2}-\dot{\hat{\alpha}}^{*}$

Using (17) and (9a-b) in (20), one gets:

$$
\begin{aligned}
& \dot{z}_{2}=\beta(x)+\frac{K_{M}}{L_{s}} u_{1} v_{d c}-\hat{J}\left(c_{1}^{2} z_{1}+\ddot{x}_{1}^{*}\right)+c_{1} z_{2}+\hat{F}\left(c_{1} z_{1}-\dot{x}_{1}^{*}\right) \\
& -\left(c_{1} z_{2}-\hat{J} c_{1}\left(c_{1} z_{1}-\dot{x}_{1}^{*}\right)\right) \frac{\tilde{J}}{J}-\hat{J} c_{1} x_{1} \frac{\tilde{F}}{J}+c_{1} \hat{J} \frac{\tilde{T}_{g}}{J} \\
& \quad+\left(c_{1} z_{1}-\dot{x}_{1}^{*}\right) \dot{\hat{J}}+\dot{\hat{T}}_{g}-\dot{\hat{F}} x_{1} \\
& \quad-\frac{\hat{F}}{J}\left[z_{2}+\tilde{J}\left(c_{1} z_{1}-\dot{x}_{1}^{*}\right)+\tilde{T}_{g}-\tilde{F} x_{1}\right]
\end{aligned}
$$

with

$\beta(x)=-K_{M}\left(-\frac{R_{s}}{L_{s}} x_{2}-p x_{3} x_{1}+\frac{K_{M}}{L_{s}} x_{1}\right)$

For convenience, error equations (19) and (20b) are rewritten here together:

$$
\begin{aligned}
\dot{z}_{1}= & -c_{1} z_{1}+\frac{1}{J}\left[z_{2}+\tilde{J}\left(c_{1} z_{1}-\dot{x}^{*}\right)+\tilde{T}_{g}-\tilde{F} x_{1}\right] \\
\dot{z}_{2}= & \gamma-\frac{F}{J} z_{2}-\frac{\tilde{J}}{J}\left(c_{1} z_{2}-\left(\hat{J} c_{1}-\hat{F}\right)\left(c_{1} z_{1}-\dot{x}_{1}^{*}\right)\right) \\
& -\frac{\tilde{F}}{J}\left(\left(\hat{J} c_{1}-\hat{F}\right) x_{1}-z_{2}\right)+\frac{\tilde{T}_{g}}{J}\left(\hat{J} c_{1}-\hat{F}\right)
\end{aligned}
$$

with

$$
\begin{aligned}
\gamma & =\beta(x)+\frac{K_{M}}{L_{s}} u_{1} v_{d c}-\hat{J}\left(c_{1}^{2} z_{1}+\ddot{x}_{1}^{*}\right)+c_{1} z_{2}+\hat{F}\left(c_{1} z_{1}-\dot{x}_{1}^{*}\right) \\
& +\left(c_{1} z_{1}-\dot{x}_{1}^{*}\right) \dot{\hat{J}}+\dot{\hat{T}}_{g}-\dot{\hat{F}} x_{1}
\end{aligned}
$$

To determine a stabilizing control law for (21a-b), let us consider the quadratic Lyapunov function candidate:

$V_{2}=0.5 z_{1}^{2}+0.5 z_{2}^{2}+\frac{1}{2 J} \tilde{J}^{2}+\frac{1}{2 J} \tilde{F}^{2}+\frac{1}{2 J} \tilde{T}_{g}^{2}$

Using (21a-b), one gets from (22) that:

$$
\begin{aligned}
\dot{V}_{2} & =z_{1} \dot{z}_{1}+z_{2} \dot{z}_{2}+\frac{\tilde{J}}{J} \dot{\tilde{J}}+\frac{\tilde{F}}{J} \dot{\tilde{F}}+\frac{\tilde{T}_{g}}{J} \dot{\tilde{T}}_{g} \\
& =-c_{2} z_{2}^{2}+\gamma z_{2}+\frac{1}{J} z_{1} z_{2}-\frac{F}{J} z_{2}^{2} \\
& +\frac{\tilde{J}}{J}\left[z_{1}\left(c_{1} z_{1}-\dot{x}_{1}^{*}\right)-c_{1} z_{2}^{2}+\left(\hat{J} c_{1}-\hat{F}\right)\left(c_{1} z_{1}-\dot{x}_{1}^{*}\right) z_{2}+\dot{\hat{J}}\right] \\
& +\frac{\tilde{F}}{J}\left[-x_{1} z_{1}+z_{2}^{2}-\left(\hat{J} c_{1}-\hat{F}\right) x_{1} z_{2}+\dot{\hat{F}}\right] \\
& +\frac{\tilde{T} g}{J}\left[z_{1}+\left(\hat{J} c_{1}-\hat{F}\right) z_{2}+\dot{\hat{T}}_{g}\right]
\end{aligned}
$$

The three last terms of the second equality (24) are canceled by choosing:

$$
\begin{aligned}
& \dot{\hat{J}}=-z_{1}\left(c_{1} z_{1}-\dot{x}_{1}^{*}\right)+c_{1} z_{2}^{2}-\left(\hat{J} c_{1}-\hat{F}\right)\left(c_{1} z_{1}-\dot{x}_{1}^{*}\right) z_{2} \\
& \dot{\hat{F}}=x_{1} z_{1}-z_{2}^{2}+\left(\hat{J} c_{1}-\hat{F}\right) x_{1} z_{2}
\end{aligned}
$$


$\dot{\hat{T}}_{g}=-z_{1}-\left(\hat{J} c_{1}-\hat{F}\right) z_{2}$

Substituting (25a-c) in (24) yields

$\dot{V}_{2}=-k_{2} z_{2}^{2}+\gamma z_{2}-\frac{F}{J} z_{2}^{2}+\frac{1}{J} z_{1} z_{2}$

which suggests to choose the term $\gamma$ so that:

$\gamma=-c_{2} z_{2}$

where $c_{2}$ is a new design parameter. Indeed, combining (27) and (22) implies that the control inputs $u_{1}$ are chosen so that:

$$
\begin{aligned}
\frac{K_{M}}{L_{s}} u_{1} v_{d c} & =-\left(c_{2}+c_{1}\right) z_{2}-\beta(x)+\hat{J}\left(c_{1}^{2} z_{1}+\ddot{x}_{1}^{*}\right) \\
& -\hat{F}\left(c_{1} z_{1}-\dot{x}_{1}^{*}\right)-\left(c_{1} z_{1}-\dot{x}_{1}^{*}\right) \dot{\hat{J}}-\dot{\hat{T}}+\dot{\hat{F}} x_{1}
\end{aligned}
$$

Substituting (27) in (26) yields:

$\dot{V}_{2}=-c_{1} z_{1}^{2}-\left(c_{2}+\frac{F}{J}\right) z_{2}^{2}+\frac{1}{J} z_{1} z_{2}$

Using the following inequalities: $\left(z_{1}^{2}+z_{2}^{2}\right) / 2 \geq z_{1} z_{2}$

Equation (29) implies:

$\dot{V}_{2} \leq-\delta\left(z_{1}^{2}+z_{2}^{2}\right)$

with $\delta=\min \left(c_{1},\left(c_{2}+F / J\right)\right)-J / 2$.

Substituting (27) in (21b) and using (21a) yields:

$$
\begin{aligned}
\dot{z}_{1}= & -c_{1} z_{1}+\left[z_{2}+\tilde{J}\left(c_{1} z_{1}-\dot{x}^{*}\right)+\tilde{T}_{g}-\tilde{F} x_{1}\right] / J \\
\dot{z}_{2}= & -c_{2} z_{2}-\frac{F}{J} z_{2} \\
& -\frac{\tilde{J}}{J}\left(c_{1} z_{2}-\left(\hat{J} c_{1}-\hat{F}\right)\left(c_{1} z_{1}-\dot{x}_{1}^{*}\right)\right) \\
& -\frac{\tilde{F}}{J}\left(\left(\hat{J} c_{1}-\hat{F}\right) x_{1}-z_{2}\right)+\frac{\tilde{T}_{g}}{J}\left(\hat{J} c_{1}-\hat{F}\right)
\end{aligned}
$$

\section{3 d-axis current regulation}

The d-axis current $x_{3}$ undergoes equation (9c) in which the following quantity is defined:

$v=p x_{2} x_{1}-u_{2} v_{d c} / L_{s}$

As the reference signal $i_{\text {dref }}$ is null, it follows that the tracking error $z_{3}=x_{3}-i_{\text {dref }}$ undergoes the equation:

$\dot{z}_{3}=-\left(R_{s} / L_{s}\right) z_{3}+v$

To get a stabilizing control signal for this first-order system, a PI control law is invoked.

$v=\left(R_{s} / L_{s}\right) z_{3}-c_{3} z_{3}-\frac{1}{T_{i o}} e_{1}$

with $e_{1}(t)=\int_{0}^{t} z_{3}(\tau) d \tau$

where $c_{3}>0$ (a new design parameter).

It also follows from (33)-(34) that $z_{3}$ undergoes the differential equation:

$\dot{z}_{3}=-c_{3} z_{3}-\frac{1}{T_{i o}} e_{1}$
The regulator parameters $\left(c_{3}, T_{i o}\right)$ are positive real constants.

\subsection{Reactive power and DC voltage controller}

In controlling a PFC, the main objective is to obtain a sinusoidal output current and the injection or extraction of a desired reactive power in the electric network. The continuous voltage $v_{d c}$ must track a given reference signal $v_{d c r e f}$. These objectives lead to two control loops. The first loop ensures the regulation of the DC voltage $x_{4}$ and the second ensures the injection of the desired reactive power.

1) DC voltage loop

Based on equations ( $9 \mathrm{~d}-\mathrm{e})$, a first equation involving the control input $u_{3}$ will now be designed, using the backstepping technique (Krstic et al., 1995), so that the squared DC-link voltage $x_{4}=v_{d c}^{2}$ tracks well any reference signal $x_{4}^{*} \stackrel{d e f}{=} v_{d c r e f}^{2}>0$. As the subsystem ( $\left.9 \mathrm{~d}-\mathrm{e}\right)$ is of relative degree 2 , the design towards that equation is performed in two steps.

Step 1. Let $z_{4}$ denote the speed tracking error:

$z_{4}=x_{4}-x_{4}^{*}$

In view of (9d), the above error undergoes the following equation:

$\dot{z}_{4}=-\frac{1}{C} E_{n d} x_{5}+\beta\left(x_{i=1 \ldots 3}, z_{i=1 \ldots 3}\right)-\dot{x}_{4}^{*}$

with,

$$
\begin{aligned}
\beta(\bullet) & =-\frac{1}{C}\left\{E_{n q} x_{6}+\frac{J L_{s}}{3 K_{M}}\left(\left(c_{1}+c_{2}\right) z_{2}-c_{1}^{2} z_{1}+\chi(x, t)\right) x_{2}\right. \\
& \left.-L_{s}\left(c_{3} z_{3}-\frac{R_{s}}{L_{s}} z_{3}+p x_{2} x_{1}\right) x_{3}\right\}
\end{aligned}
$$

In (41), the quantity $\alpha_{1}=-E_{n d} x_{5} / C$ stands up as a (virtual) control input for the $z_{4}$-dynamics because the actual control input $u_{3}$ act on $z_{4}$ indirectly through $\alpha_{1}$. Following the backstepping design technique, the Lyapunov function candidate is considered as: $V_{4}=0.5 z_{4}^{2}$. Deriving $V_{4}$ along the trajectory of (41) yields:

$\dot{V}_{4}=z_{4} \dot{z}_{4}=-z_{4}\left(\frac{1}{C} E_{n d} x_{5}-\beta(x, z)+\dot{x}_{4}^{*}\right)$

This suggests for the (virtual control) $\alpha_{1}$ the following control law:

$\alpha_{1}^{*}=-c_{4} z_{4}-\beta(x, z)+\dot{x}_{4}^{*}$

with $c_{4}>0$ a design parameter. Indeed, substituting $\alpha_{1}^{*}$ to $\alpha_{1}=-E_{n d} x_{5} / C$ gives $\dot{V}_{4}=-c_{4} z_{4}^{2}$ which clearly is negative definite in $z_{4}$. As $\alpha_{1}$ is just a virtual control input, one cannot set $\alpha_{1}=\alpha_{1}^{*}$. Nevertheless, the above expression of $\alpha_{1}^{*}$ is retained and a new error is introduced:

$z_{5}=\alpha_{1}-\alpha_{1}^{*}$ 
Using (43), it follows from (41) that the $z_{4}$-dynamics undergoes the following equation:

$\dot{z}_{4}=-c_{4} z_{4}+z_{5}$

Step 2. Now, the aim is to make the couple of errors $\left(z_{4}, z_{5}\right)$ vanish asymptotically. The trajectory of the error $z_{5}$ is obtained by time-derivation of (44) i.e.:

$\dot{z}_{5}=-\frac{E_{n d}}{C} \dot{x}_{5}+c_{4} \dot{z}_{4}+\dot{\beta}(x, z)-\ddot{x}_{4}^{*}$

Using (45) and (9d-e) in (40) yields:

$\dot{z}_{5}=\beta_{1}\left(x_{i=1 \ldots 6}, z_{i=1 . .5}\right)-\frac{E_{n d}}{C L_{0}} u_{3} v_{c d}$

with $\beta_{1}(x, z)=c_{4} \dot{z}_{4}+\dot{\beta}(x, z)-\ddot{x}_{4}^{*}+\frac{E_{n d}^{2}}{C L_{0}}-\frac{E_{n d}}{C} \omega_{n} x_{6}$

To determine a stabilizing control law for (9d-e), let us consider the quadratic Lyapunov function candidate:

$V_{5}=0.5 z_{4}^{2}+0.5 z_{5}^{2}$

Using (45)-(46), one gets from (48a) that:

$\dot{V}_{5}=-c_{4} z_{4}^{2}+z_{5}\left(z_{4}+\beta_{1}\left(x_{i=1 \ldots 6}, z_{i=1 \ldots 5}\right)-\frac{E_{n d}}{C L_{0}} u_{3} v_{c d}\right)$

This suggests the following choice for the variable $u_{3}$ :

$u_{3}=\left(c_{5} z_{5}+z_{4}+\beta_{1}\left(x_{i=1 \ldots 6}, z_{i=1 . .5}\right)\right) C L_{0} / E_{n d} v_{c d}$

where $c_{5}>0$ is a new design parameter. Indeed, substituting (49) in (48b) yields:

$\dot{V}_{5}=-c_{4} z_{4}^{2}-c_{5} z_{5}^{2}<0$

Now, substituting (49) in (47) one obtains the DC voltage closed-loop control system:

$\dot{z}_{4}=-c_{4} z_{4}+z_{5}$

$\dot{z}_{5}=-c_{5} z_{5}-z_{4}$

2) Reactive Power loop

Here, the focus is made on the control objective $\mathrm{CO} 3$ that involves the reactive power $Q_{n}$ which is required to track its reference $Q_{n}^{*}$. The electrical reactive power injected in the grid is given by $Q_{n}=E_{n d} x_{6}-E_{n q} x_{5}$. To harmonize notation throughout this section, the corresponding tracking error is denoted $z_{6}=Q_{n}-Q_{n}^{*}$. It follows from (9e-f) that $z_{6}$ undergoes the differential equation:

$\dot{z}_{6}=\beta_{2}\left(x_{5}, x_{6}\right)+\frac{v_{c d}}{L_{0}}\left(E_{n d} u_{4}-E_{n q} u_{3}\right)$

with, $\beta_{2}\left(x_{5}, x_{6}\right)=-\omega_{n}\left(E_{n d} x_{5}+E_{n q} x_{6}\right)-\dot{Q}_{n}^{*}$.

As (52) is a first order equation, it can be (globally asymptotically) stabilized using a simple proportional control law:

$v_{c d}\left(E_{n d} u_{4}-E_{n q} u_{3}\right) / L_{0}=-c_{6} z_{6}-\beta_{2}\left(x_{5}, x_{6}\right)$

with $c_{6}>0$. Then the control law $u_{4}$ is given as:

$u_{4}=\left(-L_{0}\left(c_{6} z_{6}+\beta_{2}\left(x_{5}, x_{6}\right)\right) / v_{c d}+E_{n q} u_{3}\right) / E_{n d}$
It can be easily checked that the dynamic of $z_{6}$ undergoes the following equation:

$\dot{z}_{6}=-c_{6} z_{6}$

\section{SIMULATION}

The controlled system is simulated within the Matlab/Simulink environment, using the electro-mechanical characteristics of Table 1. The controller, mathematically defined by (25), (28), (33), (49) and (54) is simulated. The numerical values (proved to be suitable) for the design parameters of the controller and the observer are chosen as follows:

$c_{1}=7 ; c_{2}=4.10^{4} ; c_{3}=10^{3} ; c_{4}=40 ; c_{5}=10^{4} ; c_{6}=2.10^{4} ; T_{i o}=100$.

The controller performances will be evaluated in presence of (time-varying) wind velocity (then rotor speed reference $\omega_{\text {ref }}$ and load torque $T_{g}$ ). According to the control design (Section $3)$, the remaining closed loop inputs are kept constant, namely $i_{\text {sdref }}=0 \mathrm{~A}, V_{\text {dcref }}=700 \mathrm{~V}$ and $Q_{\text {nref }}=0 \mathrm{VAR}$.

\begin{tabular}{ll}
\hline \multicolumn{3}{c}{ Supply network } & $380 \mathrm{~V}-220 \mathrm{~V} / 50 \mathrm{~Hz}$ \\
\hline $\begin{array}{l}\text { AC/DC/AC } \\
\text { converters }\end{array}$ & $\mathrm{L}_{0}=10 \mathrm{mH} ; \mathrm{C}=47 \mathrm{mF}, \mathrm{PWM} 10 \mathrm{KHz}$. \\
\hline $\begin{array}{l}\text { Synchronous } \\
\text { generator }\end{array}$ & $50 \mathrm{~kW} ; \mathrm{p}=4 ; \quad R_{s}=0.3 \Omega ; \quad L_{S}=17.5 \mathrm{mH}$, \\
\hline
\end{tabular}

\subsection{Illustration of optimization strategy}

Fig. 3 shows that the wind speed signal reference takes a low, medium and high value. Block optimization of speed, studied in section 3.2, generates the rotor speed reference shown in Fig.4. With such speeds, we can extract, by the synchronous wind generator, the active power shown in Fig.5. Referring to the turbine power characteristics (Fig.2), these active powers correspond to optimal values of each wind speed.

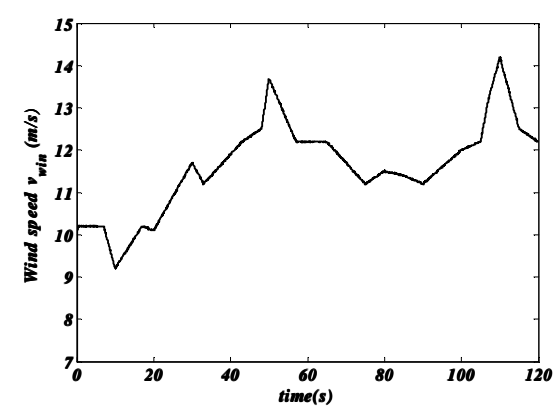

Fig.3 Wind velocity $(\mathrm{m} / \mathrm{s})$ 


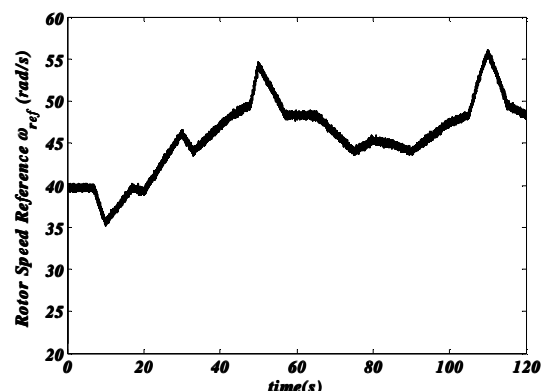

Fig.4 Optimized Rotor Speed reference

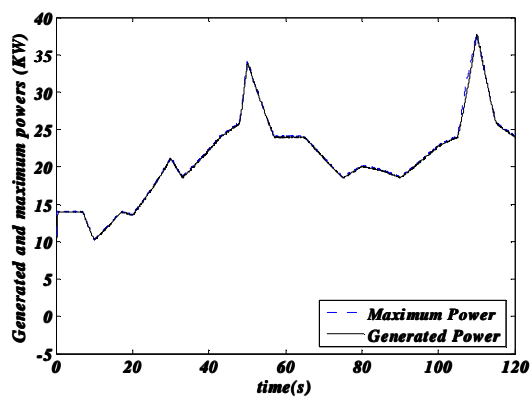

Fig.5 Generated power (KW)

\subsection{Illustration of the adaptive controller performances}

In this subsection, the controller performances are illustrated by Fig.6-10. The Fig.6-7 show that the machine speed, $x_{1}=\omega$ and the d-component of the stator current, $x_{3}=i_{s d}$ perfectly converge to their respective references. The tracking quality is quite satisfactory after each change in the wind speed. Fig. 8 shows the reactive power injected in the three-phase network $Q_{n}$ (equals zero), produced by the machine and transferred to the grid through the tri-phase inverter. Fig.9 shows that the DC-link voltage $v_{d c}$ is tightly regulated: it quickly settles down after each change in the wind speed. The wave frame of the line current $i_{n 1}$ is showed in Fig.10. The current remains (almost) all time sinusoidal and in phase with the network voltage complying with the PFC requirement.

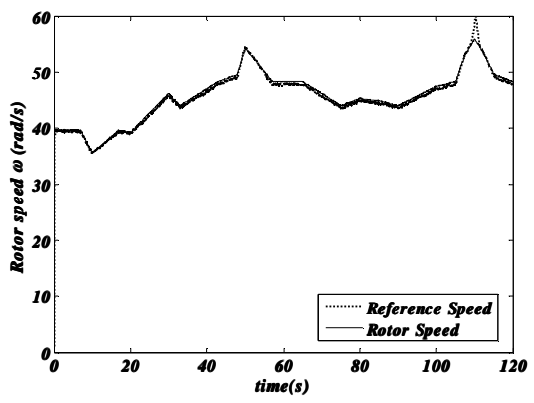

Fig.6 Reference and real rotor speed ( $\mathrm{rad} / \mathrm{s})$

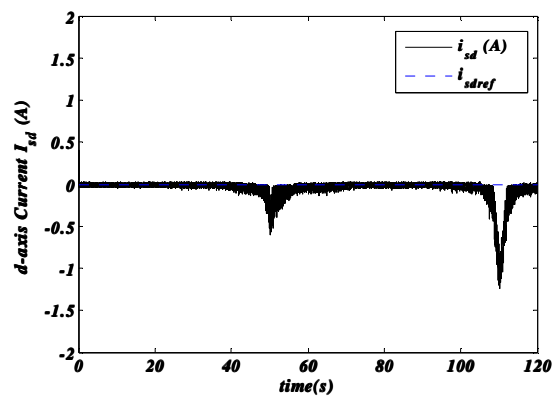

Fig.7 d-axis current $i_{s d}$ (A)

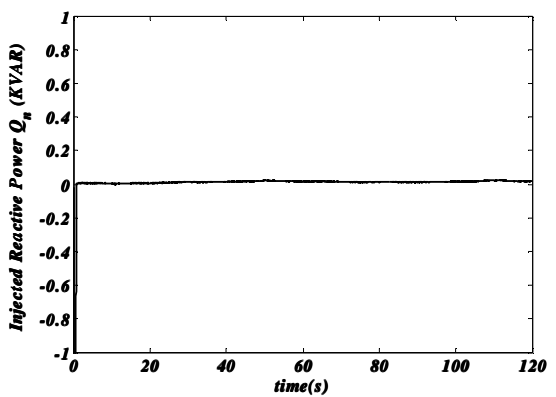

Fig.8 Reactive power injected in the network $Q_{n}$ (VAR).

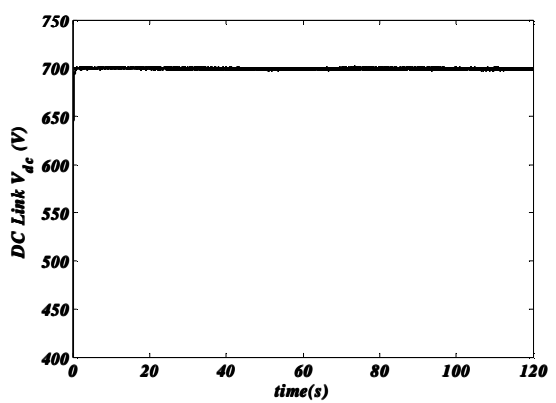

Fig. 9 DC link voltage (V).

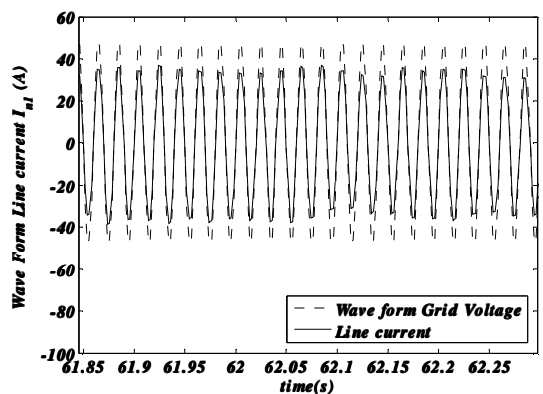

Fig.10 Wave frame of the line input current

\section{CONCLUSION}

We have addressed the problem of sensorless control of the wind energy conversion system. Maximum wind energy extraction is achieved by running the wind turbine generator in variable-speed mode without using the sensor wind velocity(????). The controlled system is an association including wind turbine, permanent magnet synchronous aerogenerator and AC/DC/AC converter connected with a triphase net work. The system dynamics have been described by the averaged $6^{\text {th }}$ order nonlinear state-space model (9a-f). The multi-loops nonlinear controller defined by the control laws (26), (32), (43) and (48) has been designed, based on the backstepping techniques. The controller has been designed to 
get: (i) a satisfactory rotor speed reference tracking for extracting maximum power; (ii) a tight regulation of the stator d-axis; (iii) a power factor correction; (iv) a well regulated DC-link voltage (vdc). These results have been confirmed by a simulation study.

\section{REFERENCES}

Senjyu T., Ochi Y., Kikunaga Y., Tokudome M., Yona A., Muhando E.B., Urasaki N., Funabashi T., (2009). 'Sensor-less maximum power point tracking control for wind generation system with squirrel cage induction generator', Renewable Energy 34 pp: 994-999, (2009).

Hong Y.-Y., Lu S.-D., Chiou C.-S, (2009). 'MPPT for PM wind generator using gradient approximation', Energy Conversion and Management 50 (1), pp. 82-89, 2009

Kesraoui M., Korichi N., Belkadi A., (2011). 'Maximum power point tracker of wind energy conversion system', Renewable Energy, vol. 36 pp. 2655-2662, (2011)

Boukhezzar B., Siguerdidjane H., (2006), 'Nonlinear Control of Variable-Speed Wind Turbines for Generator Torque Limiting and Power Optimization', J. Sol. Energy Eng., Vol 128, Issue 4, p.516, 2006.

Eftichios K., Kostas K., (2006). 'Design of a Maximum Power Tracking System for Wind-Energy-Conversion Applications', IEEE Transactions on Industrial Electronics, Vol. 53, No. 2, April 2006

Chi S., Zhang Z., Xu L., (2007). 'A novel sliding mode observer with adaptive feedback gain for PMSM Sensorless Vector Control', Power Electronics Specialists Conference, IEEE 2007, pp: 2579-258

El Magri A., Giri F., Besançon G., El Fadili A., Dugard L., Chaoui F.Z., (2013). 'Sensorless adaptive output feedback control of wind energy systems with PMS generators', Control Engineering Practice, Vol. 21, pp 530-543, 2013

El Magri A., Giri F., Abouloifa A., El fadili A., (2009). 'Nonlinear Control of Associations Including Wind Turbine, PMSG and AC/DC/AC Converters - Speed regulation and power factor correction', IEEE, European Control Conference 2009, August 23-26, 2009, Budapest, Hungary.

Krstic M., Kanellakopoulos I., Kokotovic P., (1995). 'Nonlinear and adaptive control design', John Wilay \& Sons, Inc, 1995.

Wallmark O. (2004). 'On control of permanent-magnet synchronous motors in hybrid-electric vehicle application'. Technical Report, School of Electrical Engineering, Chalmers University of technology Goteborg, Sweden.

Michael J, Ryan D., Rik W., (1998). 'Modeling of Sinewave Inverters: A Geometric Approach', Industrial Electronic Conference, IEEE Conference, 1998, vol.1, pp 396 - 401.

Grabic S., Celanovic N., Katic V.A., (2008). Permanent Magnet Synchronous Generator Cascade for Wind Turbine Application', Power Electronics, IEEE Transactions, vol 23, May 2008, pp:1136 - 1142

Muhammad H., Rashid, (2001). 'Power electronics handbook', Academic press, 2001.

Hong-Woo Kim, Sung-Soo Kim, Hee-Sang Ko, (2010). 'Modeling and control of PMSG-based variable-speed wind turbine', Electric Power Systems Research 80 (2010), pp:46-52

Sira H., Silva R.. (2006).' Control design techniques in power electronics devices'. Springer.

Tan K., Islam S., (2008). 'Optimum Control Strategies in Energy Conversion of PMSG Wind Turbine System without Mechanical Sensors', IEEE Transactions on Energy Conversion 19 (2), pp. 392-399, 2008 